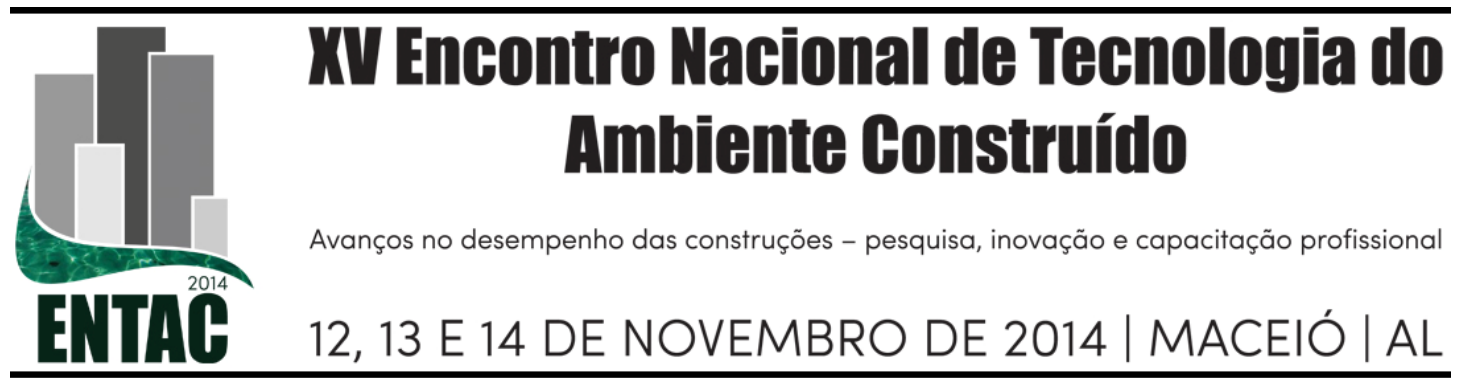

\title{
IMPACTO DO TRATAMENTO ACÚSTICO DE LAJES NO CUSTO DAS EDIFICAÇÕES RESIDENCIAIS DO CUB
}

\author{
NIENKOETTER, Gustavo Martins (1); JÚNIOR, Reginaldo Mendes \\ Santos Cardoso (2); MARCHIORI, Fernanda Fernandes (3); ROMAN, Humberto \\ Ramos (4); SOUZA, Mauricy (5)
}

(1) UFSC, (48) 9961-2927, e-mail: gnienkoetter@gmail.com (2) UFSC, (48) 8403-0787, e-mail: reginaldo_ir@hotmail.com (3) UFSC, (48) 3721-2395, e-mail: fernanda.marchiori@ufsc.br (4) UFSC, (48) 3721-2394, e-mail: humberto.roman@ufsc.br, (5) FLORAM, (48) 3721-2395, mauricycrsouza@yahoo.com.br

\begin{abstract}
RESUMO
A recentemente revisada NBR 15.575, que define o desempenho mínimo para as edificações, trouxe uma nova realidade para o desempenho das edificações no Brasil. Os principais elementos da edificação têm agora definidos com maior precisão os padrões de desempenho esperados ao longo de sua vida útil. Contudo, existe no mercado da construção uma preocupação, especialmente por parte das empresas construtoras, no que diz respeito às tecnologias a serem utilizadas e ao impacto destas no custo dos novos empreendimentos a fim de que o desempenho estabelecido na norma seja atendido. O objetivo do presente artigo, portanto, é analisar um destes aspectos: o impacto da inclusão de distintos sistemas de tratamento acústico de lajes no custo de edificações, considerando oito tipos de projetos de construção residencial previstos na metodologia de cálculo do Custo Unitário Básico (CUB) e seis tipos de sistemas para tratamento acústico para lajes, sendo que método de pesquisa empregado é a pesquisa documental. Como resultado, obteve-se que o percentual de custo máximo das soluções de tratamento acústico dos sistemas analisados ficou menor que $5 \%$ do custo da edificação, mesmo nas edificações de padrão popular do CUB. Por outro lado, verificou-se que nas empresas construtoras consultadas nesta pesquisa, a opção por um ou outro sistema de tratamento acústico de lajes ainda é algo empírico, sendo necessário que mais estudos acadêmicos e tecnológicos venham a ajudar o mercado na decisão da escolha entre sistemas a partir da análise de custo $\mathrm{x}$ desempenho acústico de cada sistema.
\end{abstract}

Palavras chave: NBR 15575; Desempenho Acústico de Laje, Custo.

\begin{abstract}
The newly revised NBR 15.575, which defines the minimum performance for buildings, brought a new reality to the performance of buildings in Brazil. The main elements of the building have now more precisely defined performance standards expected throughout his life. However, there is in the construction market a concern, especially by construction companies, with regard to the technologies to be used and the impact of the cost of new developments so that the performance established standard is met. The purpose of this article, therefore, is to analyze one of these aspects: the impact of the inclusion of different systems of acoustic treatment of slabs in the cost of buildings, considering the various construction standards set out the methodology of calculation of Basic Unit Cost (CUB) and six types of systems for acoustic treatment for slabs, and research method employed is the documentary research. As a result, it was found that the maximum cost of the solutions of acoustic treatment systems analyzed was less than $5 \%$ of the cost of the building, even in buildings popular standard CUB. Moreover, it was found that the construction companies consulted in this research, the choice of one or another system of acoustic treatment of slabs is still something empirical, requiring more academic and technologic studies will help the market in the choice decision between systems from the analysis of cost- acoustic performance of each system .
\end{abstract}

Keywords: NBR 15575. Acoustic Performance of the Slab. Treatment of Acoustic Slabs, cost. 


\section{INTRODUÇÃO}

A busca por um lugar tranqüilo em meio ao ambiente agitado das grandes cidades é, sem dúvida, um desafio para os profissionais que atuam na área do Ambiente Construído. As normas têm sido modificadas de modo a exigir maiores níveis de conforto acústico dos edifícios que estão sendo projetados e construídos. No ano de 2013 entrou em vigor a NBR 15.575:2013 - Edificações Habitacionais - Desempenho (ABNT, 2013) que delimita um desempenho mínimo para vários aspectos da edificação. Em sua Parte 3 - Pisos, a nova NBR delimita o desempenho mínimo para o sistema de piso, quanto aos fatores: desempenho estrutural, segurança contra incêndio, estanqueidade, desempenho térmico, acústico, lumínico, de durabilidade e manutenibilidade, funcionalidade e acessibilidade, conforto tátil, visual e antropodinâmico, adequação ambiental. O foco presente trabalho se dá no desempenho acústico, especificamente de lajes. $\mathrm{O}$ conforto e desempenho acústico vêm sendo um tema recorrente tanto no meio acadêmico quanto na mídia. Observa-se então uma movimentação do mercado que tenta se adaptar o quanto antes às exigências da Norma, buscando sempre aliar um custo benefício favorável. Essa concepção de conforto acústico aliado com bom desempenho dos materiais empregados nasce na fase de projeto e é possível de ser atingida através de diferentes soluções construtivas, conforme Pedroso (2007). A preocupação das empresas construtoras, por outro lado, é com relação ao impacto que tais tratamentos terão no custo da edificação.

\subsection{Objetivo}

Neste cenário, o objetivo do presente artigo é analisar o impacto de diferentes sistemas de tratamento acústico de lajes no custo das edificações dos distintos tipos de projetos multifamiliares presentes na norma NBR 12721/2006 da ABNT (2006), a qual dá diretrizes para formação do Custo Unitário Básico (CUB).

\subsection{Delimitações da pesquisa}

Na presente pesquisa não foram feitos ensaios de diferentes tratamentos acústicos, mas sim foram adotados valores de $\mathrm{L}^{\prime}{ }_{\mathrm{nT}, \mathrm{w}}$ oriundos da bibliografia, em especial da dissertação de Pedroso (2007). Apesar de constar na norma NBR 15575 que os ensaios de avaliação do ruído de impacto devem ter como base a ISO 140-7 (de ensaios de campo), foram usados dados nível de pressão sonora de ensaios de laboratório por estes serem um indicativo de que os materiais testados em laboratório, quando aplicados em campo, se considerados os cuidados de aplicação, atenderão a condição de desempenho prevista na norma $(80 \mathrm{~dB})$ por estarem distantes deste valor.

As análises de viabilidade apresentadas neste artigo serão feitas em função do custo direto de cada solução adotada, não serão levadas em conta as despesas indiretas a ela associada.

\section{REVISÃO BIBLIOGRÁFICA}

\subsection{O ruído e a Norma de Desempenho de Edificações - NBR 15575}

As ondas sonoras podem propagar-se por diferentes meios e existem fenômenos acústicos bastante complexos que interferem no desempenho dos elementos e dos recintos, como difração, ressonância, reverberação e absorção. Tais fenômenos não são tratados individualmente na NBR 15575, sendo que o enfoque é dado à propagação dos sons aéreos e dos ruídos de impacto transmitidos por corpos sólidos, como no caso dos entrepisos (CÂMARA BRASILEIRA DA INDÚSTRIA DA CONSTRUÇÃO, 2013). 
A norma de desempenho de edificações NBR 15575 (ABNT, 2013) estabelece que: para coberturas acessíveis posicionadas sobre unidades autônomas e entrepisos que separam unidades autônomas, deve ser verificado, além da isolação ao som aéreo, o isolamento de ruídos de impacto resultantes do caminhamento, queda de objetos e outros.

No que se refere à norma NBR 15.575-3, os resultados dos ensaios para avaliar o ruído de impacto indicam se o sistema avaliado atende ou não a um determinado limite ou classificação. Mesmo sendo obtidos por ensaios conforme norma ISO, alguns fatores dificultam a comparação dos resultados entre ensaios feitos em locais e por equipes e instrumentos de medição diferentes. A inexistência de avaliação da incerteza de medição, a dificuldade em calibrar a máquina geradora de impactos, os variados sistemas construtivos e a pouca experiência brasileira em realizar ensaios para avaliar o ruído de impacto são alguns desses fatores. Além disso, os resultados de ensaios feitos em campo não podem ser comparados diretamente com ensaios feitos em laboratório, pois não é possível reproduzir em laboratório as mesmas condições da obra.

A NBR 15575 (ABNT, 2013) estipula valores limites a serem alcançados no pavimento inferior referentes ao isolamento acústico aplicados às lajes de piso através do "Nível de pressão sonora de impacto padrão ponderado" ( $\left(\mathrm{L}_{\mathrm{nT}, \mathrm{w}}\right)$, o qual deve ser $\leq 80 \mathrm{~dB}$ para os sistemas de piso separando unidades habitacionais autônomas posicionadas em pavimentos distintos. Complementarmente existe uma classificação onde é possível identificar desempenho acústico Intermediário (I) e Superior (S), além do desempenho mínimo (M). Contudo, ao se tratar de uma cobertura acessível ou sistema de piso de áreas de uso coletivo (atividades de lazer e esportivas, tais como home theater, salas de ginástica, salão de festas, salão de jogos, banheiros e vestiários coletivos, cozinhas e lavanderias coletivas) sobre unidades habitacionais autônomas, existe um maior rigor quanto ao "Nível de pressão sonora de impacto padrão ponderado" ( $\left({ }^{n}{ }_{n T, w}\right)$.

Tomando-se por base um dos sistemas de tratamento proposto por Pedroso (2007), modificando-se apenas a camada interna resiliente, comparou-se o custo dos sistemas abordados no presente artigo, levando-se em consideração que todos eles atendem o limite de 80dB estabelecido na NBR 15575. Para avaliação do custo, tomaram-se por base os projetos utilizados no cálculo do Custo Unitário Básico, a seguir descrito.

\subsection{Análise de Viabilidade Econômica: Enfoque no Método do CUB}

A primeira fase do desenvolvimento de um empreendimento é o estudo de viabilidade econômica. Nesta fase é decidido se o empreendimento irá ou não ser construído. Em geral, neste momento ainda não se tem os projetos definidos, então, os limites de custo são prognosticados levando-se em conta as necessidades gerais dos clientes (área, padrão de acabamento) e um esboço do projeto, de acordo com LIU e ZHU (2007). Vários métodos podem ser utilizados para se chegar à estimativa de custo nesta fase, como: volumes e/ou áreas indicadores de custo de construção; tempo de execução; parametrização das relações geométricas e custo (OTERO, 2000, PARISOTTO, 2003), dentre outros. Marchiori (2009) afirma que o método mais difundido nacionalmente para se estimarem os custos nas fases iniciais do empreendimento é o método do Custo Unitário Básico (CUB), segundo o cálculo baseado na Norma Brasileira - NBR 12721 (ABNT, 2006).

O "CUB" é um indicador de custo amplamente utilizado pelo mercado da Construção Civil, não somente para a estimativa de custo de obras, como também para a atualização de preços de contratos. O CUB é um indicador do custo de construção estabelecido pela Lei Federal $\mathrm{n}^{\circ} 4.591 / 64$ e apurado mensalmente pelos Sindicatos da Indústria da Construção Civil (SINDUSCONs). Os indicadores do CUB são calculados a partir dos 
19 projetos padrões da NBR 12.721/2006 de onde são levantados os quantitativos, concluídos os orçamentos, traçadas as curvas $\mathrm{ABC}$ e então definidos os 25 (vinte e cinco) materiais, as 02 (duas) categorias profissionais, 01 (um) equipamento e custo administrativo (engenheiro) que tem seus preços pesquisados mensalmente pelos SINDUSCONs regionais. O CUB mais amplamente divulgado é o CUB médio (CUBm), o qual representa a média aritmética dos 8 (oito) CUB's Residenciais calculados para cada um dos projetos-padrão dessa modalidade, contudo existem 16 tipos de CUB (mostrados no Quadro 1), os quais abarcam além das edificações residenciais, outras modalidades, como as comerciais e galpões industriais.

Quadro 1 - Projetos-padrão do CUB de acordo com a NBR 12.721/2006

\begin{tabular}{|c|c|c|c|}
\hline \multicolumn{3}{|c|}{ Caracterização dos Projetos-padrão do CUB } & \multirow[b]{2}{*}{ Sigla } \\
\hline $\begin{array}{c}\text { Padrão de } \\
\text { acabamento }\end{array}$ & Descrição & Número de pavimentos & \\
\hline \multirow{3}{*}{ Baixo } & $\begin{array}{l}\text { Residência unifamiliar padrão baixo (c/ } \\
\text { dois dormitórios) }\end{array}$ & 1 & $\mathrm{R} 1-\mathrm{B}$ \\
\hline & Prédio popular padrão baixo & Térreo +3 tipos & PP-B* \\
\hline & Residência multifamiliar padrão baixo & Térreo +7 tipos & R8-B* \\
\hline \multirow{7}{*}{ Normal } & Residência unifamiliar padrão normal & 1 & $\mathrm{R} 1-\mathrm{N}$ \\
\hline & Prédio popular padrão normal & Garagem + pilotis +4 tipos & PP-N* \\
\hline & $\begin{array}{c}\text { Residência multifamiliar padrão } \\
\text { normal }\end{array}$ & Garagem + pilotis +8 tipos & $\mathrm{R} 8-\mathrm{N}^{*}$ \\
\hline & $\begin{array}{l}\text { Residência multifamiliar padrão } \\
\text { normal }\end{array}$ & Garagem + pilotis +16 tipos & $\mathrm{R} 16-\mathrm{N}^{*}$ \\
\hline & Edificação Comercial (Salas e lojas) & Garagem + térreo +8 tipos & CSL-8 \\
\hline & Edificação Comercial (Salas e lojas) & Garagem + térreo +16 tipos & CSL-16 \\
\hline & Edificação Comercial (Andar Livre) & Garagem + térreo +8 tipos & CAL-8 \\
\hline \multirow{6}{*}{ Alto } & Residência unifamiliar padrão alto & 1 & R1-A \\
\hline & Residência multifamiliar padrão alto & Garagem + pilotis +8 tipos & R8-A* \\
\hline & Residência multifamiliar padrão alto & Garagem + pilotis +16 tipos & R16-A* \\
\hline & Edificação Comercial (Salas e lojas) & Garagem + térreo +8 tipos & CSL-8 \\
\hline & Edificação Comercial (Salas e lojas) & Garagem + térreo +16 tipos & CSL-16 \\
\hline & Edificação Comercial (Andar Livre) & Garagem + térreo +8 tipos & CAL-8 \\
\hline $\begin{array}{l}\text { Residência } \\
\text { Popular }\end{array}$ & Residência popular (c/ 1 dormitório) & 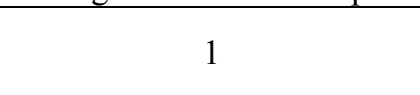 & RP1Q \\
\hline $\begin{array}{c}\text { Projeto de } \\
\text { interesse social }\end{array}$ & Residência multifamiliar & Térreo +_ 4 tipos & PIS* \\
\hline $\begin{array}{l}\text { Galpão } \\
\text { industrial }\end{array}$ & Galpão industrial & 1 & GI \\
\hline
\end{tabular}

Fonte: NBR 12.721/2006 - ABNT (2006)

*Projetos padrão abordados neste artigo.

Dentre os tipos de projetos do CUB apresentados no Quadro 1, os escolhidos para fazerem parte do presente estudo são os residenciais multifamiliares de padrão baixo, normal e alto, além do projeto de interesse social. A escolha se deu por se tratar de edificações multifamiliares, onde o ruído de impacto de uma unidade habitacional poderá interferir na unidade vizinha.

\section{METODO DE PESQUISA}

Para que o objetivo da presente pesquisa fosse atingido, foram percorridas as etapas da pesquisa apresentadas na Figura 1.

Na revisão bibliográfica foi realizada uma busca em artigos, dissertações, teses, laudos e relatórios de ensaio sobre o tema desempenho acústico de edificações. Paralelamente, 
foram feitas pesquisas sobre a formação do custo de construção, em especial dos projetos-padrão usados na formação do indicador Custo Unitário Básico (CUB).

Posteriormente foi realizada entrevista com construtoras que utilizam algum tipo de tratamento acústico com objetivo de conhecer as práticas do mercado de construção residencial multifamiliar em Florianópolis. Obteve-se a lista de empresas filiadas ao Sindicato da Indústria da Construção Civil (SINDUSCON) da Grande Florianópolis, das quais foram excluídas as que não eram construtoras de edificações residenciais multifamiliares, sendo assim selecionadas 62 empresas. A seguir foram selecionadas as que já tinham empregado as soluções de tratamento acústico de laje em seus empreendimentos, restando, então, 06 empresas. Após contatos telefônicos, três empresas se dispuseram a participar da entrevista, as quais serão citadas ao longo do texto como: Construtora A, Construtora B e Construtora C. Os aspectos levantados na entrevista foram: qual o sistema de piso, sistema de tratamento acústico e custo da solução adotada e de que forma as empresas tomam a decisão de adotar uma solução em detrimento de outra e a influência do uso de tratamento acústico nas vendas dos apartamentos.

Após a pesquisa exploratória com vistas ao entendimento do tema, procedeu-se, então, ao cálculo do custo da utilização de sistemas de tratamento acústico e seu impacto no custo de construção. As composições de custo utilizadas tiveram por base a Tabela de Composição de Preços para Orçamento - TCPO (2010), já o preço da mão de obra foi pesquisado pelo Sistema Nacional de Pesquisa de Custos e Índices da Construção Civil $\left(\right.$ SINAPI $\left.^{1}\right)$, elaborado pela Caixa Econômica Federal, referente ao mês de março 2014. Quanto ao preço dos materiais, este foi determinado através de consulta aos fabricantes.

Figura 1 - Etapas da Pesquisa

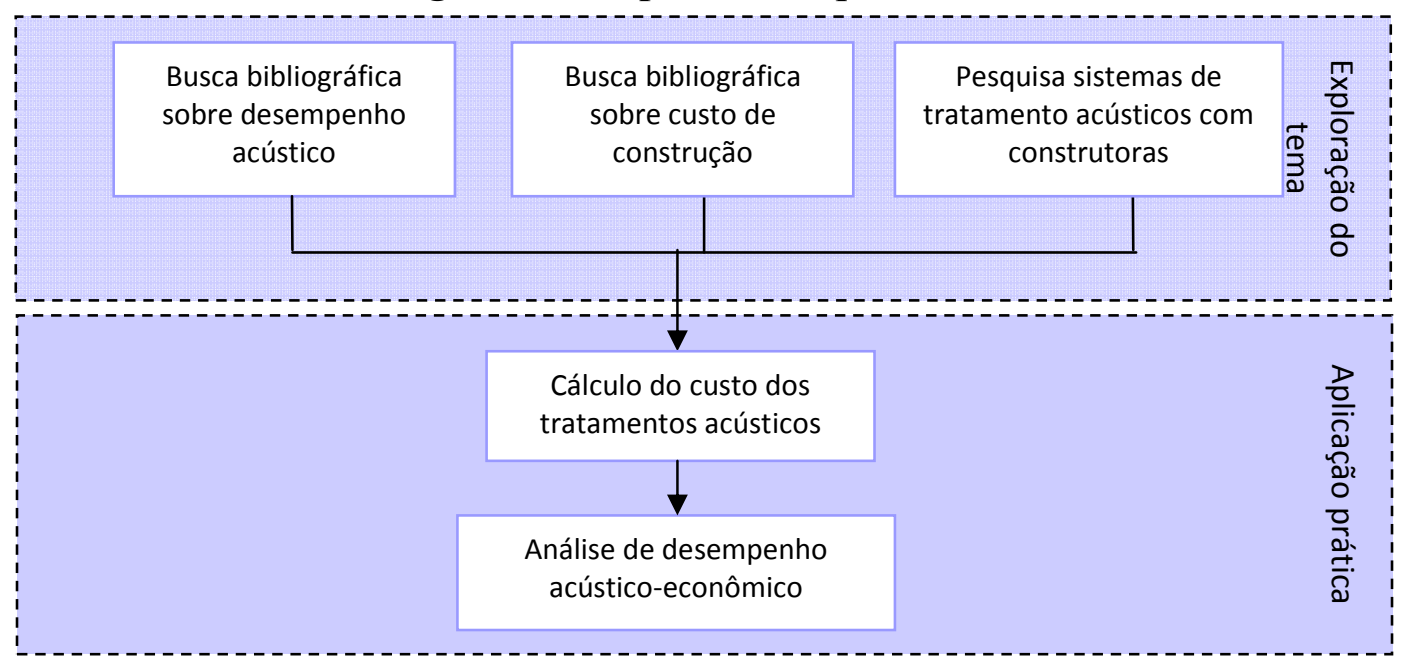

Fonte: Elaboração dos autores, 2014.

O custo global de execução foi obtido pela multiplicação da área equivalente (definida na NBR 12.721/2006), pelo valor do CUB para Florianópolis do mês de março de 2014 (SINDUSCON FLORIANÓPOLIS, 2014).

Foram, então, determinados dois custos totais de execução do projeto padrão da NBR 12.721/2006, um sem considerar o tratamento acústico e outro considerando o tratamento acústico. O custo total de execução do tratamento acústico foi obtido pela multiplicação da área de aplicação do tratamento no projeto padrão pelo custo unitário

${ }^{1}$ Foram adotados Encargos Sociais sem a desoneração de impostos. 
do serviço de execução. Desta forma foi determinada a variação de custo, em termos percentuais, do uso do tratamento acústico e comparado com o seu desempenho em termos de isolamento acústico.

\section{ANÁLISE DOS DADOS}

\subsection{Entrevistas com as construtoras}

As construtoras que fizeram parte do estudo têm sua caracterização apresentada no Quadro 2, bem como a solução de tratamento acústico por elas utilizada.

\section{Quadro 2 - Características das empresas entrevistadas e das soluções de tratamento acústico adotadas}

\begin{tabular}{|c|c|c|c|c|}
\hline & Caract.* & Caract. * & \multicolumn{2}{|c|}{ Solução de tratamento acústico adotada } \\
\hline \multirow{6}{*}{ 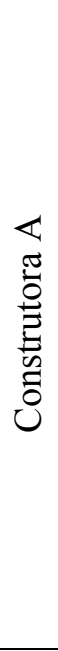 } & \multirow{6}{*}{$\begin{array}{l}\text { Grande } \\
\text { porte, } \\
\text { atuando a } \\
30 \text { anos no } \\
\text { mercado. }\end{array}$} & \multirow{6}{*}{$\begin{array}{l}\text { Médio e } \\
\text { Alto } \\
\text { padrão, } \\
\text { residencial, } \\
\text { financ/ } \\
\text { próprio. }\end{array}$} & Tipo de laje & $\begin{array}{l}\text { Laje nervurada com blocos de EPS com espessura } \\
\text { de } 17 \mathrm{~cm} \\
\text { Espessura total do sistema de piso com } \\
\text { revestimentos }=25 \mathrm{~cm}\end{array}$ \\
\hline & & & Contrapiso & Argamassa com brita leve \\
\hline & & & $\begin{array}{l}\text { Tratamento } \\
\text { acústico }\end{array}$ & $\begin{array}{l}\text { A empresa considera que o uso de EPS como } \\
\text { tratamento acústico. }\end{array}$ \\
\hline & & & $\begin{array}{l}\text { Revestimento } \\
\text { de piso }\end{array}$ & Porcelanato assentado com argamassa colante \\
\hline & & & $\begin{array}{l}\text { Revestimento } \\
\text { de teto }\end{array}$ & $\begin{array}{l}\text { Chapisco, emboço e reboco com areia fina, massa } \\
\text { corrida e pintura. }\end{array}$ \\
\hline & & & $\begin{array}{l}\text { Avaliação do } \\
\text { sistema }\end{array}$ & $\begin{array}{l}\text { Não realizam ensaios. O retorno dos clientes foi } \\
\text { melhor quando utilizada laje nervurada com EPS do } \\
\text { que com o sistema de laje pré-moldada } \\
\text { anteriormente adotada (ambos utilizavam os } \\
\text { mesmos sistemas de contrapiso e de revestimentos) }\end{array}$ \\
\hline \multirow{6}{*}{ 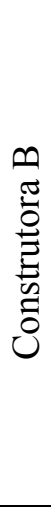 } & \multirow{6}{*}{$\begin{array}{l}\text { Grande } \\
\text { porte, } \\
\text { atuando a } \\
15 \text { anos no } \\
\text { mercado. }\end{array}$} & \multirow{6}{*}{$\begin{array}{l}\text { Médio e } \\
\text { Alto } \\
\text { padrão, } \\
\text { residencial } \\
\text { e } \\
\text { comercial, } \\
\text { financ/ } \\
\text { próprio. }\end{array}$} & Tipo de laje & $\begin{array}{l}\text { Maciça ou pré-moldada (vigotas de concreto e } \\
\text { tavelas cerâmicas) }\end{array}$ \\
\hline & & & Contrapiso & Argamassa convencional \\
\hline & & & $\begin{array}{l}\text { Tratamento } \\
\text { acústico }\end{array}$ & $\begin{array}{l}\text { Manta resiliente de } 4 \mathrm{~mm} \text { composta por fibras } \\
\text { recicladas de PET (definida em projeto de } \\
\text { tratamento acústico) }\end{array}$ \\
\hline & & & $\begin{array}{l}\text { Revestimento } \\
\text { de piso }\end{array}$ & Porcelanato assentado com argamassa colante \\
\hline & & & $\begin{array}{l}\text { Revestimento } \\
\text { de teto }\end{array}$ & $\begin{array}{l}\text { Chapisco, emboço e reboco com areia fina, massa } \\
\text { corrida e pintura. }\end{array}$ \\
\hline & & & $\begin{array}{l}\text { Avaliação do } \\
\text { sistema }\end{array}$ & $\begin{array}{l}\text { Não realizam ensaios. Não haviam feito avaliação } \\
\text { pós-ocupação. }\end{array}$ \\
\hline \multirow{6}{*}{ 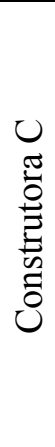 } & \multirow{6}{*}{$\begin{array}{l}\text { Grande } \\
\text { porte, } \\
\text { atuando a } \\
5 \text { anos no } \\
\text { mercado. }\end{array}$} & \multirow{6}{*}{$\begin{array}{l}\text { Alto } \\
\text { padrão } \\
\text { residencial, } \\
\text { financ/ } \\
\text { próprio }\end{array}$} & Tipo de laje & Laje nervurada com EPS com espessura de $27 \mathrm{~cm}$ \\
\hline & & & Contrapiso & Argamassa convencional. \\
\hline & & & $\begin{array}{l}\text { Tratamento } \\
\text { acústico }\end{array}$ & $\begin{array}{l}\text { A empresa considera o uso de EPS como } \\
\text { tratamento acústico. }\end{array}$ \\
\hline & & & $\begin{array}{l}\text { Revestimento } \\
\text { de piso }\end{array}$ & Porcelanato assentado com argamassa colante \\
\hline & & & $\begin{array}{l}\text { Revestimento } \\
\text { de teto }\end{array}$ & $\begin{array}{l}\text { Chapisco, emboço e reboco com areia fina, massa } \\
\text { corrida e pintura. }\end{array}$ \\
\hline & & & $\begin{array}{l}\text { Avaliação do } \\
\text { sistema }\end{array}$ & $\begin{array}{l}\text { Não realizam ensaios. Não haviam feito avaliação } \\
\text { pós-ocupação. }\end{array}$ \\
\hline
\end{tabular}

*Caract $=$ Caracterização 


\subsection{Cálculo dos custos dos sistemas de tratamento acústico}

Para efetuar o cálculo do custo dos sistemas de tratamento acústico, adotou-se uma das configurações de sistemas de tratamento acústico proposta por Pedroso (2007), o qual contém: laje em concreto armado, sobre ela: camada de material resiliente (mantas apresentadas no Quadro 3), contrapiso e, dando o acabamento, o piso em porcelanato, conforme apresentado na Figura 2. É importante salientar que a camada "material resiliente" é que tem variações, sendo usados diferentes tipos de materiais para tanto.

\section{Figura 2 - Camadas do sistema de tratamento acústico avaliado}

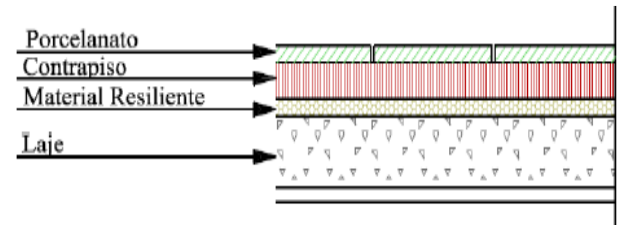

Fonte: Pedroso (2007)

As composições de custo escolhidas na TCPO que mais se assemelham a instalação de mantas acústicas e execução de camadas de regularização foram, respectivamente: “07220.8.1.2 - Isolamento térmico em laje", unidade: $\mathrm{m}^{2}$ (adaptada para os casos onde o piso flutuante for executando com mantas de material resiliente) e a composição "09605.8.1.7 - Regularização sarrafeada de base para revestimento de piso com argamassa de cimento, unidade: $\mathrm{m}^{2}$ " (adaptada para o caso do piso flutuante com Brita Leve), já que não existiam as composições de custo no TCPO que refletissem exatamente os serviços encontrados na prática de obra de Florianópolis. Desta forma, para a instalação de manta de material resiliente, chegou-se a um custo de $\mathrm{R} \$ 10,44$ acrescido do valor da manta $\left(\right.$ por $\mathrm{m}^{2}$ ). Já para a regularização sarrafeada de base para revestimento de piso com argamassa de cimento e brita leve, o custo foi de R\$16,49 (por $\mathrm{m}^{2}$ ). No Quadro 3 estão apresentados os preços para os materiais com base nos valores de mercado das mantas acústicas, bem como, o preço final do serviço.

Quadro 3 - Valores totais do serviço para cada sistema

\begin{tabular}{|c|c|c|c|c|c|c|}
\hline Num. & Material & $\begin{array}{c}\text { Espessura } \\
\mathbf{( m m )}\end{array}$ & $\begin{array}{c}\text { Densidade } \\
\mathbf{( k g / \mathbf { m } ^ { 3 } )}\end{array}$ & $\begin{array}{c}\text { Valor Mão } \\
\mathbf{d e} \text { Obra } \\
\mathbf{( R S )}\end{array}$ & $\begin{array}{c}\text { Valor } \\
\text { Material } \\
\mathbf{( R S )}\end{array}$ & $\begin{array}{c}\text { Valor Total } \\
\text { do Serviço } \\
\mathbf{( R \$ / \mathbf { m } )}\end{array}$ \\
\hline 1 & Lã de Vidro & 15,0 & 60,0 & 10,44 & 28,70 & 39,14 \\
\hline 2 & $\begin{array}{c}\text { Manta de Borracha } \\
\text { Reciclada }\end{array}$ & 8,0 & 130,0 & 10,44 & 85,00 & 95,44 \\
\hline 3 & $\begin{array}{c}\text { Manta de Borracha } \\
\text { Reciclada }\end{array}$ & 4,0 & 260,0 & 10,44 & 40,00 & 50,44 \\
\hline 4 & $\begin{array}{c}\text { Poliestireno } \\
\text { Expandido }\end{array}$ & 25,0 & 27,5 & 10,44 & 3,95 & 14,39 \\
\hline 5 & $\begin{array}{c}\text { Poliestireno } \\
\text { Expandido }\end{array}$ & 25,0 & 32,5 & 10,44 & 5,26 & 15,70 \\
\hline 6 & EVA (brita leve) & $5,0 / 7,0$ & 100,0 & 8,99 & 7,50 & 16,49 \\
\hline
\end{tabular}

Fonte: Elaboração dos autores, 2014.

\section{IMPACTO DO CUSTO DO TRATAMENTO ACÚSTICO NOS PROJETOS PADRÕES DO CUB}

No Quadro 4 estão apresentados os valores (em reais e percentualmente) de custo do tratamento acústico com relação ao custo dos empreendimentos considerando os projetos-padrão residenciais do CUB. 
Quadro 4 - Custo de 6 tipos de tratamento acústico para cada projeto padrão do CUB

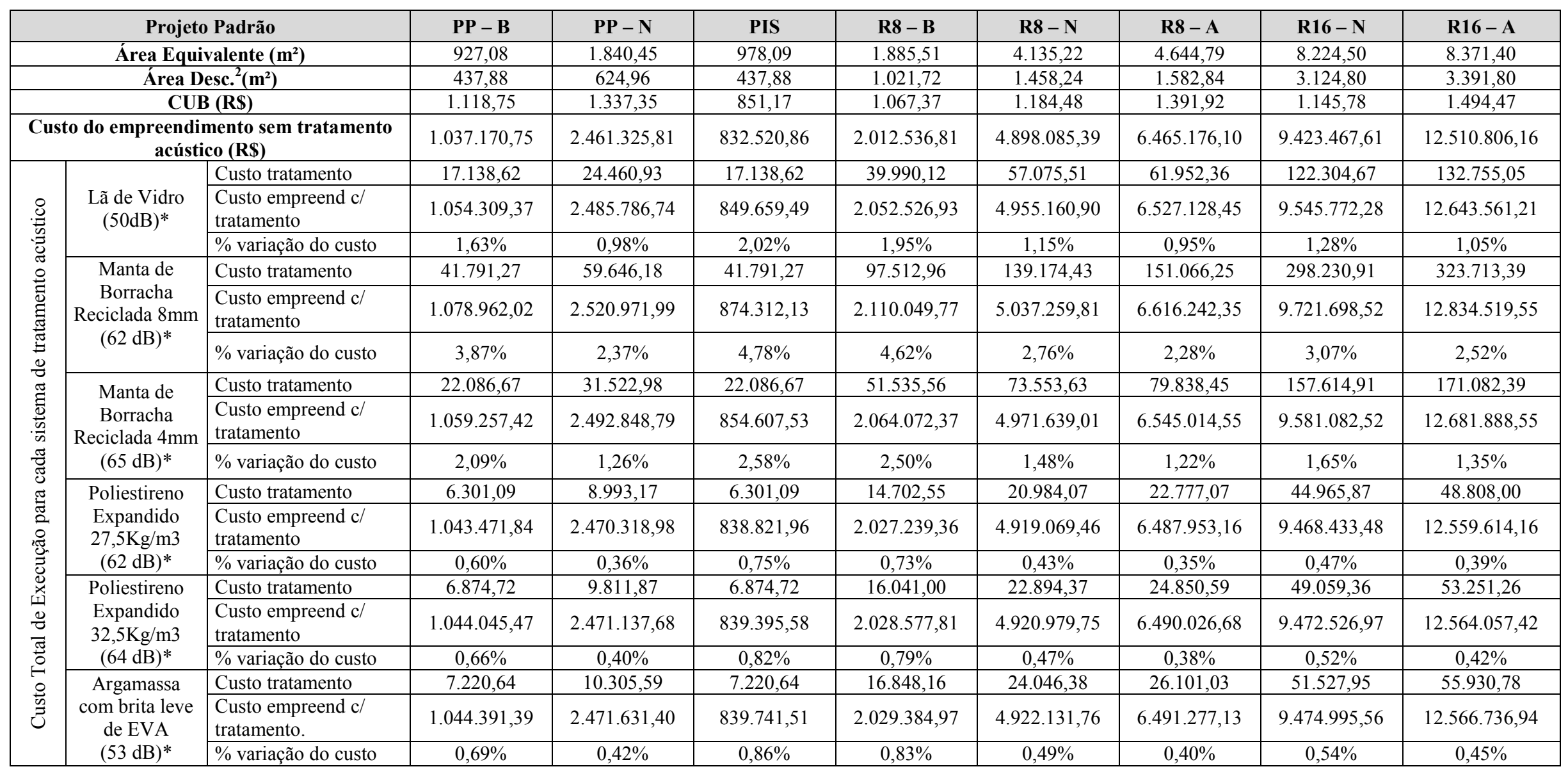

*Valores de Ln,w (dB) extraídos da dissertação de mestrado de Pedroso (2007), calculados à partir da ISO 140-6 considerando-se o revestimento de piso como sendo porcelanato em todos os casos.

\footnotetext{
${ }^{2}$ Área Descontada: Área subtraída da área total dos projetos padrão referente as áreas onde não são instalados os materiais para tratamento acústico, como por exemplo cozinha, banheiros, áreas comuns.
} 
Como era esperado, o maior impacto no custo se dá no projeto que tem o menor custo de construção por área, o projeto de interesse social (PIS). Neste tipo de construção, o valor do tratamento acústico irá variar de 0,75 até $4,78 \%$ do custo total de construção, sendo que o tratamento de menor custo é utilizando-se o poliestireno expandido de densidade $27,5 \mathrm{Kg} / \mathrm{m} 3$ e o de maior custo é a manta de borracha reciclada de $8 \mathrm{~mm}$. A diferença de isolação acústica entre eles é de $10 \mathrm{~dB}$, sendo, entre ambos, o poliestireno expandido, o elemento com melhor desempenho acústico.

Se o percentual de participação do tratamento acústico no custo do empreendimento for colocado em ordem crescente em cada tipo de projeto do CUB, perceber-se-á que a lógica de influência no custo se mantém para todos os padrões de acabamentos e número de pavimentos, por exemplo: a manta de borracha reciclada de 8 $\mathrm{mm}$ foi a mais cara em todos os tipos de projeto e o poliestireno expandido, o mais barato.

Interessante observar que o tratamento acústico mais barato (poliestireno expandido de densidade $27,5 \mathrm{Kg} / \mathrm{m}^{3}$ ) não foi o de pior desempenho acústico, de acordo com os dados de $\mathrm{L}_{\mathrm{nT}, \mathrm{w}}$ apresentados por Pedroso (2007). A lã de vidro foi o tratamento que se mostrou com melhor desempenho e a um custo intermediário dentre as 6 soluções analisadas. Poder-se-ia apontar, ainda, o tratamento acústico contendo a brita leve de EVA na argamassa de contrapiso como um material promissor a ser desenvolvido como sistema acústico, já que seu custo também foi intermediário e apresentou o segundo melhor nível de isolamento acústico.

\section{CONSIDERAÇÕES FINAIS}

O objetivo do presente trabalho foi atingido ao se apresentar, no Quadro 4, o impacto do tratamento acústico de lajes utilizando distintos sistemas no custo das edificações dos projetos residenciais multifamiliares presentes na norma do CUB:NBR 12721 (2006). Foi possível mostrar, ainda, que as soluções acústicas possuem, em geral, um baixo custo quando comparado ao custo total da edificação, mas que sofrem influência de acordo com o padrão de acabamento da edificação, sendo mais relevantes nos de padrão mais baixo. O impacto econômico no custo dos projetos populares é algo importante de ser levado em conta por parte dos órgãos financiadores, principalmente nas obras dos Programas Habitacionais Federais, como o "Minha Casa Minha Vida", a fim de considerá-los nas verbas destinadas ao Programa, a fim de fomentar uso de tratamento acústico em lajes, mesmo em habitações mais simples.

Com relação às soluções adotadas pelas construtoras estudadas em Florianópolis, verifica-se que a escolha do sistema de tratamento acústico é feita, muitas vezes, por indicação de fabricantes sem a busca da verificação "in loco" do atendimento às normas técnicas. É importante ressaltar que as soluções utilizadas nas construtoras $\mathrm{A}$, B e C não tiveram associação com as soluções de tratamento adotadas pelos autores apresentadas no Quadro 3. De qualquer forma julga-se importante conhecer a prática do mercado com relação aos tratamentos acústicos de laje, apesar de não se terem dados de quanto eles são eficientes. Faz-se, portanto, necessário, um engajamento do Setor local, a fim de atender a norma de desempenho (NBR 15.575), a fim de que desempenho acústico das soluções adotadas sejam comprovados. Outros trabalhos acadêmicos também poderiam ser desenvolvidos, como, por exemplo: no desenvolvimento de novos produtos para tratamento acústico; pesquisas variando as características do elemento laje (variando espessuras e acabamentos)a fim de auxiliarem 
o mercado na decisão da escolha entre sistemas a partir da análise de custo $\mathrm{x}$ desempenho acústico de cada sistema.

\section{REFERÊNCIAS BIBLIOGRÁFICAS}

ASSOCIAÇÃO BRASILEIRA DE NORMAS TÉCNICAS. NBR 12721. Avaliação de custos unitários de construção para incorporação imobiliária e outras disposições para condomínios edilícios: Procedimento. Rio de Janeiro, 2006.

ASSOCIAÇÃO BRASILEIRA DE NORMAS TÉCNICAS. NBR 15.575:Edificações habitacionais - Desempenho - Parte 3: Requisitos para os sistemas de pisos. Rio de Janeiro, 2013.

ASSOCIAÇÃO BRASILEIRA DE NORMAS TÉCNICAS. NBR 15.575:Edificações habitacionais - Desempenho - Parte 1: Requisitos Gerais. Rio de Janeiro, 2013.

CAIXA ECONÔMICA FEDERAL (Brasília) (Org.). Sistema Nacional de Pesquisa de Custos e Índices da Construção Civil. 1ed Brasília: Caixa Econômica Federal, 2014. $105 \mathrm{p}$.

CÂMARA BRASILEIRA DA INDÚSTRIA DA CONSTRUÇÃO - CBIC. Desempenho de edificações habitacionais: guia orientativo para atendimento à norma ABNT NBR 15575/2013. Fortaleza: Gadioli Cipolla Comunicação, 2013. 300 p.

CÂMARA BRASILEIRA DA INDÚSTRIA DA CONSTRUÇÃO. GUIA ORIENTATIVO PARA ATENDIMENTO À NORMA ABNT NBR 15575/2013. 2013. 300 f. Gadioli Cipolla Comunicação. Fortaleza, 2013.

EDITORA PINI LTDA (São Paulo) (Org.). Tabelas de Composição de Preços para Orçamentos. 13ed, São Paulo: Pini, 2010. 640 p.

LIU, L.; ZHU, K. Improving cost estimates of construction projects using phased cost factors. Journal of Construction Engineering and Management, v.133, n. 1, 2007, p. 91-95.

MARCHIORI, F. F. Desenvolvimento de um método para elaboração de redes de composições de custo para orçamentação de obras de edificações. 2009. 239 f. Tese (Doutorado) - Programa de Pós Graduação de Engenharia Civil, Universidade de São Paulo, São Paulo, 2009.

OTERO, J.A. Análise paramétrica de dados orçamentários sobre estimativas de custos para a construção de edifícios: um estudo de caso voltado para a questão da variabilidade. 2000. 249p. Dissertação (Mestrado) - Universidade Federal de Santa Catarina. Florianópolis, 2000.

PARISOTTO, J.A. Análise de estimativas paramétricas para formular um modelo de quantificação de serviços, consumo de mão-de-obra e custo de edificações residenciais: estudo de caso para uma empresa construtora. 2003. Dissertação (Mestrado) - Universidade Federal de Santa Catarina. Florianópolis, 2003.

PEDROSO, Miguel Angelo Pedroso. Estudo Comparativo entre as Modernas Composições de Pisos Flutuantes quanto ao Desempenho no Isolamento ao Ruído de Impacto. 2007. 141 f. Dissertação (Mestrado em Engenharia Civil) - Universidade Federal de Santa Maria, Santa Maria, 2007.

SINDUSCON FLORIANÓPOLIS. CUB Residencial. Disponível em: http://sindusconfpolis.org.br/index.asp?dep=57\&nomeDep=planilha-completa . Acesso em: 07/04/2014. 